Research Paper

\title{
Overcome the Seasonal Constraint for Somatic Embryogenesis Using In vitro Leaf Explants and Genetic Fidelity Testing of Sapindus mukorossi
}

\author{
REETIKA SINGH ${ }^{1}$, NISHI KUMARI ${ }^{1, *}$ and MAJOR SINGH ${ }^{2}$ \\ ${ }^{1}$ Department of Botany, MMV, Banaras Hindu University, Varanasi 221 005, Uttar Pradesh, India \\ ${ }^{2}$ Indian Institute of Vegetable Research, Jakhini, Varanasi 231 304, Uttar Pradesh, India
}

(Received on 31 July 2018; Revised on 19 May 2019; Accepted on 22 June 2019)

\begin{abstract}
Sapindus mukorossi is an imperative medicinal and economical tree. The fruit of this tree is as a primary source of saponins. The aim of the current study was to develop a regeneration protocol of Sapindus plant from in vitro leaf explants to overcome the seasonal constraints. An efficient somatic embryogenesis protocol was developed by using in vitro leaf explants. Maximum callusing was found in MS medium supplemented with BAP. All the calli (100\%) produced somatic embryos and a number of somatic embryos (47.10 $\pm 1.04 \mathrm{a})$ were observed on MS medium supplemented with $8.88 \mu \mathrm{M}$ BAP. Maximum maturation percentage of somatic embryos (95.52 $\pm 0.31 \mathrm{a})$ was observed on MS medium supplemented with $4 \% \mathrm{w} / \mathrm{v}$ sucrose and $0.0378 \mu \mathrm{M}$ abscisic acid (ABA). Highest germination percentage of somatic embryos (77.79 $\pm 0.66 \mathrm{a})$ was observed on MS basal medium having 4\% w/v sucrose and $4.44 \mu \mathrm{M}$ BAP. About $80 \%$ plants survived in field condition and grew well. The field transferred plants showed similar morphology as the mother plants. Random amplified polymorphic-DNA and inter-simple sequence repeats analysis also showed analogous banding pattern with mother plants that indicated there are no somaclonal variations.
\end{abstract}

Keywords: Somatic Embryogenesis; In vitro Leaf Explants; Genetic Fidelity; Sapindus mukorossi; Molecular Markers

Abbreviations: RAPD-random amplified polymorphic-DNA; ISSR-inter simple sequence repeats; BAP-6benzylaminopurine; TDZ-Thidiazuron; 2,4-D- 2,4-Dichlorophenoxyacetic acid; KIN-Kinetin; IAAindole-3 acetic acid; IBA-indole-3 butyric acid; FE-frequency of embryogenesis; IE-Intensity of embryogenesis; ABA-Abscisic Acid

\section{Introduction}

Somatic embryogenesis delivers an admirable morphogenetic system for investigating the cellular and molecular process underlying differentiation (Benelli et al. 2001) and it is also a model system for studying the genetic basis of embryogenesis and totipotency of somatic cells (Feher et al. 2003). It is the most effective method of micropropagation to produce true-to-true type plantlets of valuable and elite genotype for large-scale multiplication in short time period (Lema-Ruminska et al. 2013). Somatic embryos (SE) also offer the opportunity to produce artificial seeds and appreciated tools for genetic engineering and germplasm conservation by cryopreservation (Ara et al. 2000; Litz and Gray 1995).
In the woody tree system, various explants such as cotyledons and zygotic embryonic axis (Murraya konigii), leaf (Olea europaea and Sapindus mukorossi), rachis ( $S$. mukorossi), sepals ( $S$. trifoliatus) etc. have been used for induction of somatic embryogenesis (Paul et al. 2011; Mazri et al. 2013; Singh et al. 2015; Singh et al. 2016a; Asthana et al. 2017). In vitro leaf (IVL) explants have also been used for induction of SE in the rose plant (Kim et al. 2004). Generally the auxins have been reported for the induction of somatic embryogenesis but in few reports cytokinins also showed significant role in induction of somatic embryogenesis. Cytokinins play important role in cell division and differentiation. Cytokinins also have the ability to induce caulogenesis and somatic

*Author for Correspondence: E-mail: kumaridrnishi@yahoo.co.in,nishi.kumari5@bhu.ac.in 
embryogenesis (Deo et al. 2010). Among all cytokinins, BAP (Singh et al. 2015; Singh et al. 2016a; Martin 2004; Manjula et al. 2000) and thidiazuron (TDZ) (Mithila et al. 2003; Lin et al. 2004) showed more efficacies for somatic embryogenesis induction. High level of endogeneous auxins in explants promotes the somatic embryogenesis in the medium containing cytokinins (Singh et al. 2015).

Maintenance of genetic integrity is a key for large-scale multiplication of $i n$ vitro plants. The genetic fidelity can be evaluated by isozyme electrophoresis. The modern day PCR based molecular markers such as random amplified polymorphic-DNA (RAPD), simple sequence repeats (SSR), inter simple sequence repeats (ISSR), amplified fragment length polymorphism (AFLP), or Restriction fragment length polymorphism (RFLP) etc. are some of the clonal fidelity methods that are rapid and easy for detection of somaclonal variations. ISSR proved to be more effective and reproducible for detecting genetic uniformity (Martins et al. 2004), whereas RAPD marker is easy in handling and cost effective also. The limited number of informative makers and its proneness to developmental and environmental variations are the major restraints of this technique (Rani et al. 1995).

Sapindus mukorossi Gaertn. (familySapindaceae) is a well-known economical and medicinal tree. Fruits contain large amount of saponins, but conventional propagation is not enough to accomplish the extensive demand of soap industry. This plant possesses various pharmacological properties such as antioxidant activity (Singh and Kumari 2015; Singh and Kumari 2020), antibacterial and antifungal activity (Singh et al. 2016b; Singh et al. 2016c; Tsuzuki et al. 2007), hepatoprotective (Ibrahim et al. 2008), and anti-cancer activity (Man et al. 2010) etc. The present research paper deals with the regeneration of $S$. mukorossi through somatic embryogenesis by using in vitro leaf explants and assessment of genetic fidelity through RAPD and ISSR markers.

\section{Material and Methods}

\section{Source of Explants, Culture Media and Culture Conditions}

Leaves were harvested from the in vitro plants, raised by following the protocol described by Singh et al. (2015). Leaf explants were inoculated after removal of the apical and basal portion.Culture media and culture conditions were similar to the earlier published reports of Singh et al. (2015).

\section{Callus Induction and Development of Somatic Embryos}

For callus induction, leaf explants were cultured on full strength MS medium having 3\% (w/v) sucrose and $0.8 \%(\mathrm{w} / \mathrm{v})$ agar supplemented with different concentrations of PGRs such as 2,4Dichlorophenoxyacetic acid (2,4-D) (2.26, 4.52, 9.04, 13.56 or $22.65 \mu \mathrm{M})$, 6-benzylaminopurine (BAP) (2.22, $4.44,8.88,13.32$ or $22.2 \mu \mathrm{M})$, kinetin $(\mathrm{KIN})(2.32$, $4.64,9.28,13.92$ or $23.25 \mu \mathrm{M})$, indole-3 acetic acid (IAA) $(2.85,5.7,11.4,17.1$ or $28.55 \mu \mathrm{M})$ or indole-3 butyric acid (IBA) $(2.45,4.9,9.8,14.7$ or $24.5 \mu \mathrm{M})$. After callus initiation, cultures were sub-cultured either on a medium of the same composition or on MS basal medium for callus proliferation and initiation of SE.

\section{Role of Media Supplements on Induction of Somatic Embryos}

To evaluate the effect of sucrose concentration on SE induction, embryogenic calli were transferred to MS basal medium with different concentrations of sucrose $(1,2,3,4,5$ or $6 \% \mathrm{w} / \mathrm{v})$. Embryogenic calli were also transferred to MS medium fortified with different concentrations of casein hydrolysate (100, 200,300 or $400 \mathrm{mgl}^{-1}$ ).

\section{Maturation and Germination of Somatic Embryos}

For maturation of somatic embryos, early cotyledon stage somatic embryos were transferred to MS medium supplemented with different concentrations of sucrose $(1,2,3,4,5$ or $6 \% \mathrm{w} / \mathrm{v})$. Different concentrations of ABA $(0.000378,0.00378,0.0378$, 0.378 or $0.756 \mu \mathrm{M}$ ) were also tried in the medium containing $4 \% \mathrm{w} / \mathrm{v}$ sucrose for maturation of embryos.

Mature embryos were transferred to either MS basal medium with different concentrations of sucrose $(1,2,3,4,5$ or $6 \% \mathrm{w} / \mathrm{v})$ or MS medium $+4 \% \mathrm{w} / \mathrm{v}$ sucrose and supplemented with different concentrations of BAP $(4.44,8.88$ or $13.32 \mu \mathrm{M})$. 


\section{Field Transfer of Plantlets and Genetic Fidelity Testing}

Hardening, acclimatization and field transfer processes followed were similar to as reported by Singh et al. (2015).

Total ten samples were processed for genetic fidelity assessment (mother plant M1 and M2 + eight in vitro raised plants R1-R8). Genetic fidelity was assessed using PCR based RAPD and ISSR analysis. About $200 \mathrm{mg}$ young leaves of the mother plant and in vitro raised plants were used for DNA extraction by following the standard method of Doyle and Doyle (1990). A similar procedure was used as earlier reported by Singh et al. (2016).

\section{Experimental Design and Data Analysis}

For each treatment, twenty replicates were used and each experiment was repeated thrice. The cultures were examined at regular intervals of one week each. The results were expressed as a mean $\pm \mathrm{SE}$ of three independent experiments. The data were analysed statistically using one-way analysis of variance (ANOVA) and significant differences between means were assessed by Tukey's multiple range tests at $p \leq 0.001$ using SPSS (version 16). Frequency of somatic embryogenesis was calculated in terms of $\%$ cultures showing somatic embryo formation, whereas, intensity of embryos was calculated by calculating average number of somatic embryos per culture.

\section{Results and Discussion}

IVL explants have shown robust embryogenic potential similar to that of leaf explants of this plant. In vitro raised explants not only overcome the limitations of seasonal availability of explants but also seasonal variations in embryogenic responses. In vitro explants are more juvenile and have high and fast regeneration potential as compared to in vivo explants.

\section{Effect of Different Growth Regulators on Callusing}

Callusing induction was observed on MS media supplemented with different concentrations of 2,4-D, BAP or KIN. Maximum percentage callusing (100\%) was observed on MS media supplemented with 4.44, 8.88 or $13.32 \mu \mathrm{M}$ BAP (Fig. 1a). But callus formed on $8.88 \mu \mathrm{M}$ BAP was more friable and embryogenic in nature, so, further experiments were carried out using this callus. However, maximum percentage callusing of leaf explants was found only on $8.88 \mu \mathrm{M}$ BAP supplemented medium (Singh et al., 2015). Hundred percent callusing by in vitro leaf explants on suitable media may be due to less development of vasculature and poor differentiation of tissue.

MS media supplemented with different concentrations of 2,4-D or KIN were not effective for callus induction as compared to BAP containing media. Callus induction was also observed on media containing different concentrations of KIN but the callusing percentage was very low. Among various concentrations of KIN, maximum percent callusing $(44.10 \pm 0.66 \mathrm{a})$ was observed on $13.92 \mu \mathrm{M}$ KIN supplemented medium. Similarly in many plants, somatic embryogenesis induced by cytokinins have been observed (Lakshmanan and Taji 2000; Sagare et al., 2000; Kaparakis and Alderson 2002). There are several parameters which affect somatic embryo formation, such as endogenous and/or exogenously supplied plant growth regulators (Claudia et al., 2016). In present study, presence of endogenously hormones especially auxins might have played a crucial role.

\section{Induction of SE and Development of Somatic Embryos}

Callus formed on all concentrations of BAP showed embryogenic responses when transferred to MS basal medium (Fig. 1b) but the frequency of embryogenesis (FE) and intensity of embryos (number of somatic embryos) differed. Maximum FE (100\%) was observed from the calli, whose induction media was MS medium supplemented with 4.44 or $8.88 \mu \mathrm{MBAP}$

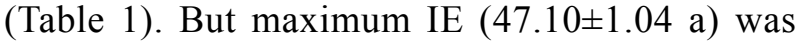
observed from the callus transferred from MS medium with $8.88 \mu \mathrm{M}$ BAP to MS basal medium. In case of in vivo leaf explants, initiation and development of somatic embryos took place on MS medium supplemented with $8.88 \mu \mathrm{M}$ BAP. But, in case of IVL explants somatic embryos developed on MS basal media. The maximum number of somatic embryos was observed on MS medium containing 3\% w/v sucrose. Effect of sucrose concentrations on the development of somatic embryos on MS basal medium has been reported in other plants such as Sapindus trifoliatus (Asthana et al., 2017), Quercus rubra 

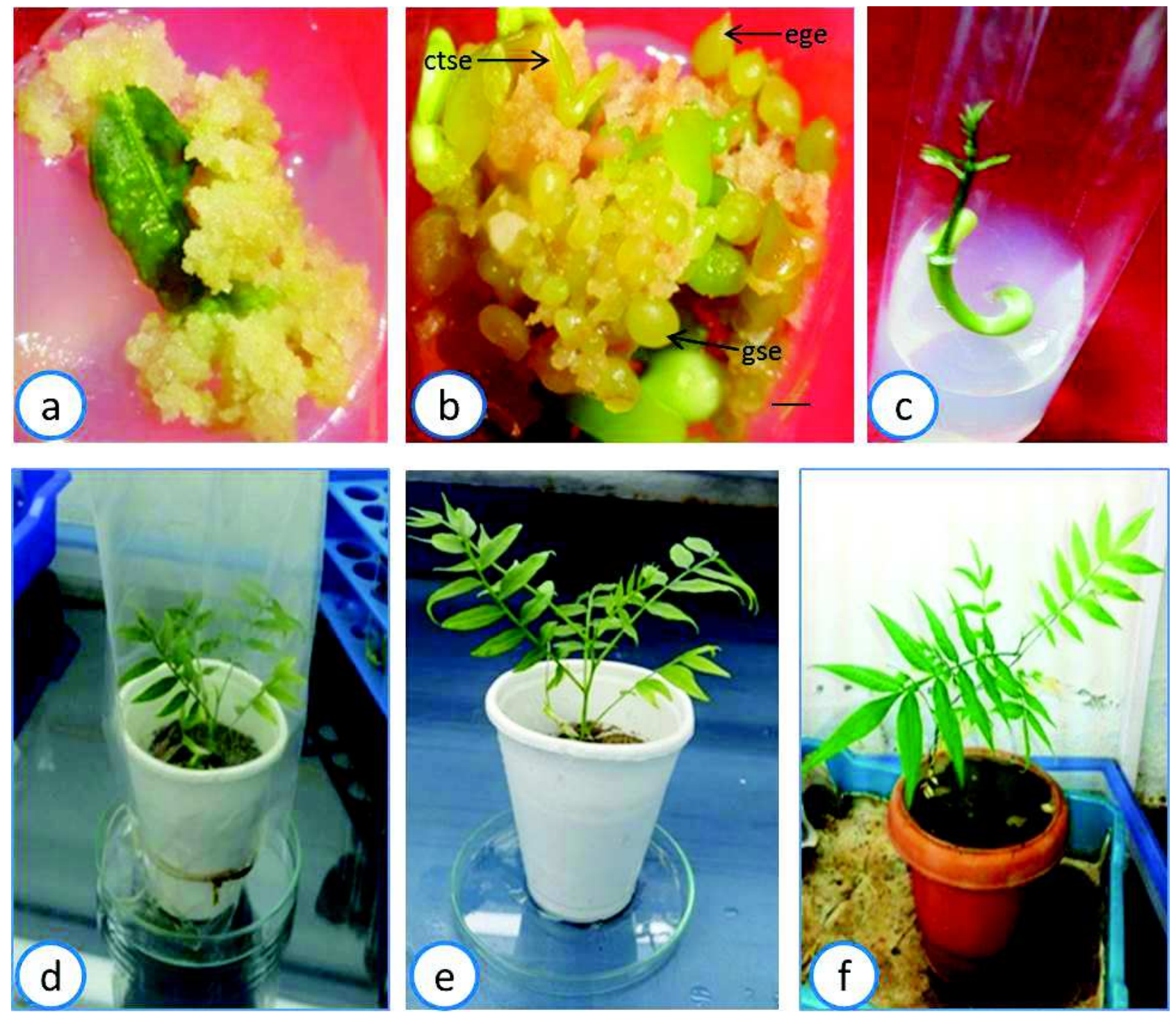

Fig. 1: Somatic embryogenesis from in vitro leaf explant of in $S$. mukorossi (a-f). a-Initiation of callusing, b- Asynchronous development of somatic embryos, c-Germination of somatic embryos, d-hardening of plantlets, e-acclimatization, fField transferred plantlet in pot, (gse-globular stage embryo, ege-elongated globular embryo, ctse-cotyledonary stage embryo, Bar scale $=2 \mathrm{~mm}$ )

(Vengadesan and Pijut 2009), and Eucalyptus camaldulensis (Prakash and Gurumurthi 2010).

\section{Maturation and Germination of Somatic Embryos}

About $88.81 \%$ somatic embryos showed maturation on MS basal medium with $4 \% \mathrm{w} / \mathrm{v}$ sucrose. Maturation percentage of somatic embryos increases by the addition of ABA in media. Maximum maturation $(95.52 \pm 0.31 \mathrm{a})$ was observed on MS medium supplemented with $4 \% \mathrm{w} / \mathrm{v}$ sucrose and $0.0378 \mu \mathrm{M}$ ABA. Presence of ABA in maturation medium enhances the physiological maturity and produces higher quality of somatic embryos (Deo et al. 2010). Promoter effects of ABA on the maturation of somatic embryos were also reported in Psidium guajava (Rai et al. 2007), and Corydalis yanhusuo (Kuo et al. 2002). ABA-induced an enhancement in protein, polyamines, free proline and starch levels as a response to desiccation tolerance in somatic embryos of sugarcane (Nieves et al. 2001). ABA also plays an important role in inhibition of precocious germination of somatic embryos and promotes the accumulation of reserve food materials (Singh et al. 2016a; Rai et al. 2011). 
Table 1. Development of somatic embryos on MS basal medium from calli formed from different concentration of BAP

\begin{tabular}{lcc}
\hline BAP $(\mu \mathrm{M})$ & FE $($ Mean \pm SE $)$ & IE $($ Mean \pm SE $)$ \\
\hline 2.22 & $35.70 \pm 1.06 \mathrm{c}$ & $16.74 \pm 0.80 \mathrm{~d}$ \\
4.44 & $100.0 \pm 0.00 \mathrm{a}$ & $28.80 \pm 0.64 \mathrm{~b}$ \\
8.88 & $100.0 \pm 0.00 \mathrm{a}$ & $47.10 \pm 1.04 \mathrm{a}$ \\
13.32 & $49.58 \pm 0.68 \mathrm{~b}$ & $24.78 \pm 1.34 \mathrm{bc}$ \\
17.76 & $40.77 \pm 0.88 \mathrm{c}$ & $19.34 \pm 0.44 \mathrm{~cd}$ \\
22.2 & $24.75 \pm 0.68 \mathrm{~d}$ & $14.98 \mathrm{~d}$ \\
\hline
\end{tabular}

Medium: $\mathrm{MS}+3 \% \mathrm{w} / \mathrm{v}$ sucrose $+0.8 \% \mathrm{w} / \mathrm{v}$ agar. All data are highly significant at $p \leq 0.001$.

Mean values followed by the different letter under different treatments within a column are significantly different from each other at $p \leq 0.001$ (Tukey's multiple range test). Letter (a-d) is from higher to lower values of the observation

Among different concentrations of sucrose tried, maximum germination percentage $(67.58 \pm 0.58 \mathrm{~b})$ was observed on MS basal medium with $4 \% \mathrm{w} / \mathrm{v}$ sucrose (Table 2). Combined role of sucrose and BAP was observed on the germination of somatic embryos (Table 2). Optimum medium for germination was MS medium with $4 \% \mathrm{w} / \mathrm{v}$ sucrose and $4.44 \mu \mathrm{M}$ BAP and an enhanced germination $(77.79 \pm 0.66$ a) was found on this media (Fig. 1c). Somatic embryos developed

Table 2: Effect of sucrose and BAP on germination of somatic embryos

\begin{tabular}{lcc}
\hline Sucrose $(w / v \%)$ & $\begin{array}{c}\text { BAP } \\
(\mu \mathrm{M})\end{array}$ & $\begin{array}{c}\text { Germination }(\%) \\
(\text { Mean } \pm \mathrm{SE})\end{array}$ \\
\hline 1 & 0 & $20.97 \pm 0.72 \mathrm{f}$ \\
2 & 0 & $41.00 \pm 1.47 \mathrm{e}$ \\
3 & 0 & $58.61 \pm 1.12 \mathrm{~d}$ \\
4 & 0 & $67.58 \pm 0.58 \mathrm{~b}$ \\
5 & 0 & $62.15 \pm 0.81 \mathrm{~cd}$ \\
6 & 0 & $40.03 \pm 0.94 \mathrm{e}$ \\
4 & 2.22 & $73.56 \pm 0.93 \mathrm{ab}$ \\
4 & 4.44 & $77.79 \pm 0.66 \mathrm{a}$ \\
4 & 8.88 & $65.11 \pm 0.67 \mathrm{~cd}$ \\
\hline
\end{tabular}

Medium: $\mathrm{MS}+0.8 \% \mathrm{w} / \mathrm{v}$ agar with different concentrations of sucrose or BAP. All data are significant at $p \leq 0.001$. Mean values followed by the different letter under different treatments within a column are significantly different from each other at $p \leq$ 0.001 (Tukey's multiple range test). Letter (a-d) is from higher to lower values of the observation from in vivo leaf explants of this plant have shown maximum germination on MS medium supplemented with $8.88 \mu \mathrm{M}$ BAP (Singh et al. 2015). Germination of embryos developed from IVL explants required a lower concentration of BAP for germination; it may be due to the presence of high concentration of endogenous cytokininin IVL explants. The efficiency of germination is a major factor for the success of plant regeneration (Singh et al. 2016; Martinelli and Mandolino 2009). Germination of somatic embryos at higher concentration of sucrose was also reported in Psidium guajava (Rai et al. 2007) and germination of somatic embryos in BAP supplemented media was reported in Quercus rubra (Vengadesan and Pijut 2009).

\section{Field plantation and Genetic Fidelity Analysis}

Micropropagated plants were successfully hardened and acclimatized in a mixture of red sand and soilrites (3:2) (Fig. 1d-e). About 80\% plants survived under field condition (Fig. 1f).

RAPD and ISSR photographs showed clear, scorable and monomorphic bands. In RAPD, total 27 bands were observed with 6 primers and the average number of bands was 4.5 (Fig. 2). In ISSR, the total number of bands was 30 with 10 primers and the average number of bands was 3 (Table 3 and Fig. 2). Amplification bands showed the genetic similarity between mother and in vitro raised plants. Presence of monomorphic bands in both RAPD and ISSR assays shows that use of IVL for regeneration purpose is safe, and there is no adverse effect of invitro conditions and culture media, as both mother plants and cultures have been maintained in in-vitro conditions for the longer duration. Combinations of both markers have been used by several researchers to assess the genetic stability in many micropropagated plants such as Spilanth esacmella (Yadav et al. 2014), Sapindus mukorossi (Singh et al. 2019) and Simmond siachinensis (Kumar et al. 2011).

\section{Conclusions}

In vitro plants of $S$. mukorosssi successfully regenerated using IVL explants through somatic embryogenesis pathways. The use of IVL explants overcomes the seasonal variations that affect the explants' responses. Genetic fidelity testing proved the genetic similarity between the mother plants and 


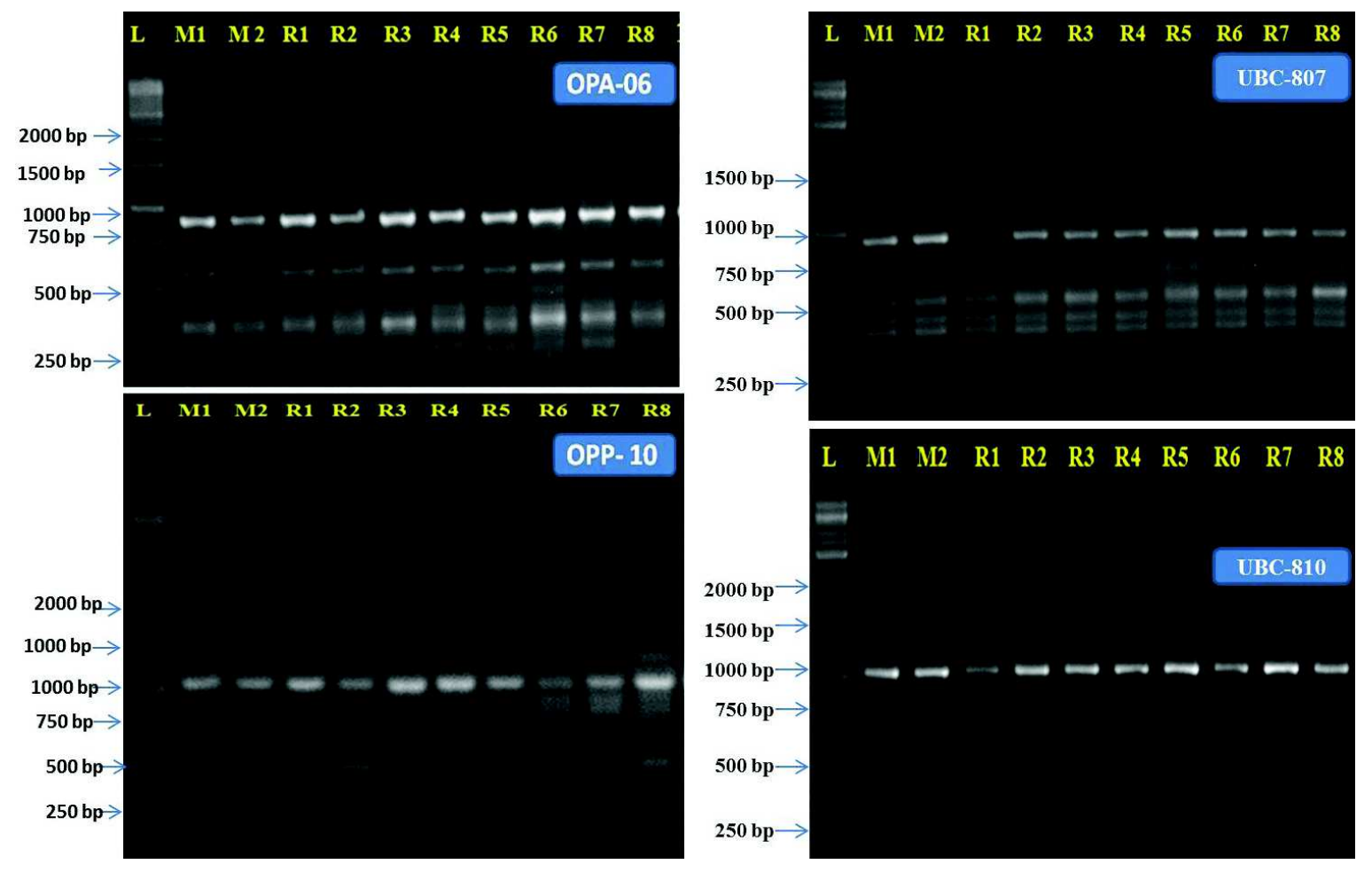

Fig. 2: RAPD amplified molecular profile with primers OPA-06 and OPP-10 and ISSR amplified molecular profile with primers UBC-807 and UBC-810 for mother plant and randomly selected regenerated plants (L-molecular ladder-1 Kb, M1 \& M2-mother plant, R1-R8 the micropropagated plants)

Table 3: DNA-based primers amplified for in vitro raised plants from in vitro leaf explants

\begin{tabular}{|c|c|c|c|c|}
\hline RAPD primer & Primer sequences & $\begin{array}{c}\text { Total no. of } \\
\text { bands amplified }\end{array}$ & $\begin{array}{c}\text { No. of scorable } \\
\text { bands }\end{array}$ & $\begin{array}{c}\text { Range of } \\
\text { amplification (bp) }\end{array}$ \\
\hline OPE-03 & CCAGATGCAC & 80 & 8 & $350-1250$ \\
\hline OPA-06 & GGTCCCTGAC & 30 & 3 & $350-950$ \\
\hline OPE-12 & TTATCGCCCC & 50 & 5 & $350-1200$ \\
\hline OPC-07 & GTCCCGACGA & 60 & 6 & $400-1200$ \\
\hline OPP-10 & TCCCGCCTAC & 20 & 2 & $500-1000$ \\
\hline OPH-04 & GGAAGTCGCC & 30 & 3 & $350-650$ \\
\hline Total & & 270 & 27 & \\
\hline \multicolumn{5}{|l|}{ ISSR Primer } \\
\hline UBC-824 & тСТСТСТСТСТСТСТCG & 20 & 2 & $400-800$ \\
\hline UBC-834 & AGAGAGAGAGAGAGACYT & 40 & 4 & $250-900$ \\
\hline UBC-856 & ACACACACACACACACCTA & 20 & 2 & $400-1000$ \\
\hline UBC-825 & ACACACACACACACACT & 40 & 4 & $500-1150$ \\
\hline UBC-814 & СТСТСТСТСТСТСТСТА & 30 & 3 & $450-950$ \\
\hline UBC-807 & AGAGAGAGAGAGAGAGT & 40 & 4 & $400-900$ \\
\hline UBC-810 & GAGAGAGAGAGAGAGAT & 20 & 2 & $400-1100$ \\
\hline UBC-840 & GAGAGAGAGAGAGAGAY & 30 & 3 & $400-1250$ \\
\hline UBC-842 & GAGAGAGAGAGAGAGAYG & 30 & 3 & $450-950$ \\
\hline UBC-854 & тСТСТСТСТСТСТСТCAGG & 30 & 3 & $700-1250$ \\
\hline Total & & 300 & 30 & \\
\hline
\end{tabular}

Note: 10 samples (plants) were tested 
regenerated plants. This regeneration protocol will be beneficial for production of a large number of in vitro plants without genetic variations in the limited time period. The in vitro raised plants, callus and in vitro raised leaf can also be used as raw materials for the production of natural antioxidants, and other important phytochemicals and pharmacophores. Production and isolation of saponins is also possible by using this reliable and reproducible protocol.

\section{References}

Asthana P, Jaiswal V S and Jaiswal U (2011) Micropropagation of Sapindus trifoliatus L. and assessment of genetic fidelity of micropropagated plants using RAPD analysis Acta Physiol Plant 33 1821-1829

Asthana P, Rai M K and Jaiswal U (2017) Somatic embryogenesis from sepal explants in Sapindustrifoliatus, a plant valuable in herbal soap industry Indus Crops Prod 100 228-235

Benelli C, Fabbri A, Grassi S, Lambardi M, Rugini E (2001) Histology of somatic embryogenesis in mature tissue of olive (Olea europaea L.) J Hort Sci Biotechnol 76 112-119

Claudia G, Fabio C, Seth F, Alex-Alan A, Marcio C, Carlos M J, Ray S, Jean-Philippe M (2016) Optimization of somatic embryogenesis procedure for commercial clones of Theobroma cacao L. African J Biotech 15 1936-1951

Deo P C, Tyagi A P, Taylor M, Harding R and Becker D (2010) Factors affecting somatic embryogenesis and transformation in modern plant breeding The South Pacific J Nat Appl Sci 28 27-40

Doyle J J and Doyle J L (1990) Isolation of plant DNA fresh tissue Focus 12 13-15

Fehér A, Pasternak T P and Dudits D (2003) Transition of somatic plant cells to an embryogenic state Plant Cell Tiss Org Cult 74 201-228

Ibrahim M, Khaja M N, Aara A, Khan AA, Habeeb M A, Devi Y P, et al. (2008) Hepatoprotective activity of Sapindus mukorossi and Rheum emodi extracts: in vitro and in vivo studies World J Gastroenterol 14 2566-2571

Kaparakis G and Alderson P G (2002) Influence of high concentrations of cytokinins on the production of somatic embryos by germinating seeds of tomato, aubergine and pepper J Hortic Sci Biotechnol 77 186-190

Kim C K, Oh J Y, Chung J D, Burell A M and Byrne D H (2004) Somatic embryogenesis and plant regeneration from in vitro grown leaf explants of Rose Hort Sci 39 1378-1380

Kumar S, Mangal M, Dhawan A K and Singh N (2011) Assessment of genetic fidelity of micropropagated plants of Simmondsia

\section{Acknowledgments}

First author (RS) is highly thankful to Council of Scientific and Industrial Research (CSIR), New Delhi, India, for providing fellowship as JRF (junior research fellow).

chinensis (Link) Schneider using RAPD and ISSR markers Acta Physiol Plant 33 2541-2545

Kuo C L, Sagare A P, Lo S F, Lee C Y, Chen C C and Tsay H S (2002) Abscisic acid promotes development of somatic embryos on converted somatic embryos of Corydalis yanhusuo (Fumariaceae) J Plant Physiol 159 423-427

Lakshmanan P and Taji A (2000) Somatic embryogenesis in leguminous plants Plant Biol 2 136-148

Lema-Ruminska J, Goncerzewicz K and Gabriel M (2013) Infuence of abscisic acid and sucrose on somatic embryogenesis in Cactus Copia poatenuissima Ritt. Form mostruosa. The Scientific World J, article ID 713985, http:/ /dx.doi.org/10.1155/2013/513985

Lin C S, Lin C C and Chang W C (2004) Effect of thidiazuron on vegetative tissue-derived somatic embryogenesis and flowering of bamboo Bambus aedulis Plant Cell Tiss Org Cult 76 75-82

Litz R E and Gray D J (1995) Somatic embryogenesis for agricultural improvement World J Microbiol Biotechnol 11 416-425

Man S, Gao W, Zhang Y, Huang L and Liu C (2010) Chemical study and medical application of saponins as anti-cancer agents Fitoterapia $\mathbf{8 1}$ 703-714

Manjula S, Job A and Nair G M (2000) Somatic embryogenesis from leaf derived callus of Tylophora indica (Burm. f.) Merril Ind J Exp Biol 38 1069-1072

Martins M, Sarmento D and Oliveira M M (2004) Genetic stability of micropropagated almond plantlets as assessed by RAPD and ISSR markers Plant Cell Rep 23 492-496

Martinelli L and Mandolino G (2009) Strategies for effective somatic embryogenesis in grapevine (Vitis spp.): An appraisal In: Roubelakis-Angelakis, KA, (ed), Grapevine molecular physiology and biotechnology, Springer, 612

Nieves N, Martinez M E, Castillo R, Blanco M A and GonzalezOlmedo J L (2001) Effect of abscisic acid and jasmonic acid on partial desiccation of encapsulated somatic embryos of sugarcane Plant Cell Tiss Org Cult 65 15-21 
Paul S, Dam A, Bhattacharyya A and Bandyopadhyay T K (2011) An efficient regeneration system via direct and indirect somatic embryogenesis for the medicinal tree Murray akoenigii Plant Cell Tiss Org Cult 105 271-283

Prakash M G and Gurumurthi K (2010) Effects of type of explant and age, plant growth regulators and medium strength on somatic embryogenesis and plant regeneration in Eucalyptus camaldulensis Plant Cell Tiss Org Cult 100 13-20

Rai M K, Akhtar N and Jaiswal V S (2007) Somatic embryogenesis and plant regeneration in Psidium guajava L. cv. Banarasi local Sci Hort 113 129-133

Rai M K, Shekhawat N S, Harish, Gupta A K, Phulwaria M, Ram $\mathrm{K}$ and Jaiswal U (2011) The role of abscisic acid in plant tissue culture - a review of recent progress Plant Cell Tiss Org Cult 106 179-190

Rani V, Parida A and Raina S N (1995) Random amplified polymorphic DNA (RAPD) markers for genetic analysis in micropropagated plants of Populus deltoidecs Marsh Plant Cell Rep 14 459-462

Sagare A P, Lee Y L, Lin T C, Chen C C and Tsay H S (2000) Cytokinin induced somatic embryogenesis and plant regeneration in Corydalis yanhusuo (Fumariaceae)-a medicinal plant Plant Sci 160 139-147

Singh R and Kumari N (2015) Comparative determination of phytochemicals and antioxidant activity from leaf and fruit of Sapindus mukorossi Gaertn. - A valuable medicinal tree Indus Crops Prod 73 1-8

Singh R, Rai M K and Kumari N (2015) Somatic embryogenesis and plant regeneration in Sapindus mukorossi Gaertn. from leaf-derived callus induced with 6-benzylaminopurine $\mathrm{Appl}$ Biochem Biotechnol 177 498-510
Singh R, Kashyap S P, Kumari N and Singh M (2016a) Regeneration of soapnut tree through somatic embryogenesis and assessment of genetic fidelity through ISSR and RAPD markers Physiol Mol Biol Plants 22 381389

Singh R, Kumari N and Nath G (2016b) Free radicals scavenging activity and antimicrobial potential of leaf and fruit extracts of Sapindus mukorossi Gaertn. against clinical pathogen Int J Phytomed 8 22-28

Singh R, Kumari N and Nath G (2016c) Antimicrobial Efficacy of Callus and in vitro Leaf Extracts of Sapindus mukorossi Gaertn. Against Pathogenic Microbes Mathews J Pharma Sci 0109

Singh R, Akhtar S and Kumari N (2019) Genetic homogeneity appraisal of in-vitro plants regenerated from leaf explants of Sapindus mukorossi using RAPD and ISSR molecular markers Res J Biotechnol 14 131-136

Singh R and Kumari N (2020) Sapindus mukorossi Gaertn.: Rich Source of Antioxidants and Reducing agents Res J Chem Environ 24 38-46

Tsuzuki J K, Svidzinski T I E, Shinobu C S, Silva L F A, Rodrigues-Filho E, Cortex D A G, et al. (2007) Antifungal activity of the extracts and saponins from Sapindus saponaria L. An Acad Bras Cienc 79 577-583

Vengadesan G and Pijut P M (2009) Somatic embryogenesis and plant regeneration of northern red oak (Quercus rubra L.) Plant Cell Tiss Org Cult 97 141-149

Yadav K, Aggarwal A and Singh N (2014) Genetic fidelity assessment of micropropagated Spilanthes acmella (L.) Murr. by RAPD markers assay Ind J Biotechnol $13274-$ 277. 